\title{
Um complexo de redes bem tecido: os tecelões da fábrica Santo Aleixo e suas relações para além do local de trabalho
}

\author{
Juçara da Silva Barbosa de Mello* \\ Felipe Augusto dos Santos Ribeiro**
}

Resumo: O presente artigo tem por objetivo analisar as experiências dos trabalhadores têxteis da Fábrica Santo Aleixo durante a Segunda Guerra e suas implicações na formação de classe. Para tal empreendimento, partiremos das proposições de Mike Savage, destacando a insegurança estrutural dos trabalhadores; a relevância do lugar como constituinte da formação de classe; bem como seus diferentes tipos de redes de contato (vínculos "densos" e "de amplo alcance"). Em relação a essas redes, pretendemos apontar os "dois tipos de vínculo", relacionando diversos atores do mundo do trabalho (os trabalhadores; os empresários; o Estado; os partidos políticos; as instituições religiosas, entre outros), tendo como ponto de partida uma discussão sobre a memória da "harmonia social" em Santo Aleixo.

Palavras-chave: Formação de classe — Redes sociais — Trabalhadores têxteis

Abstract: This article aims to review the experiences of the textile workers of the Santo Aleixo Factory during World War II and its implications for class formation. For this project, we will consider the propositions of Mike Savage, with emphasis the structural insecurity of workers; the significance of the place as a constituent of class formation; as well as their different types of networking (links "dense" and "long range"). For these networks, we intend to point out the "two types of links" linking various actors in the world of work (workers, businessmen, the State, political parties, religious institutions, among others), taking as a starting point discussion on the memory of "social harmony" in Santo Aleixo.

Keywords: Class formation — Social networks — Textile workers

* Doutora em História pela Pontifícia Universidade Católica do Rio de Janeiro (PUC-Rio) e Mestre em História Social pela Faculdade de Formação de Professores da Universidade do Estado do Rio de Janeiro (FFPUERJ). Atualmente, é professora no Departamento de História da PUC-Rio. E-mail: jsbmello@oi.com.br

** Doutorando em História, Política e Bens Culturais pelo Centro de Pesquisa e Documentação de História Contemporânea do Brasil da Fundação Getúlio Vargas (CPDOC/FGV) e Mestre em História Social pela FFP/ UERJ. Atualmente, é auxiliar do Centro de Memória da Imigração da Ilha das Flores. E-mail: felipe_ffp@ yahoo.com.br 


\section{Introdução}

[...] Tudo passou, meu filho. Tudo. Você um dia vai ser pai e vai também descobrir como são difíceis certos momentos na vida de um homem. Parece que nada dá certo, provocando um desespero interminável. Mas agora, não. Papai foi nomeado gerente da Fábrica de Santo Aleixo. Nunca mais vai faltar nada nos seus sapatinhos na noite de Natal. [...] Não chore, meu filho. Nós vamos ter uma casa muito grande. Um rio de verdade passa bem atrás. Grandes árvores e tantas, que serão só suas. Você pode fazer, armar balanços. ${ }^{1}$

Foi recebendo essa notícia que o menino Zezé, personagem principal do livro Meu Pé de Laranja Lima, sentiu o retorno de uma "nuvem de paz" sobre sua família, após severo período de desemprego.

A obra, considerada o maior sucesso editorial de José Mauro de Vasconcelos, foi publicada pela primeira vez em 1968, chegando a ser traduzida para diversas línguas. Nela, o autor lança mão de sua própria experiência de vida para discutir as dores e as angústias da infância diante das constantes mudanças de vida provocada pelos adultos.

José Mauro de Vasconcelos nasceu no bairro de Bangu, cidade do Rio de Janeiro, onde funcionava uma importante fábrica de tecidos, a Companhia Progresso Industrial do Brasil, presente em grande parte das histórias contadas em seu livro.

Para o personagem Zezé, a fábrica trazia más lembranças: "Não gostava dela. [...] A Fábrica era um dragão que todo dia comia gente e de noite vomitava o pessoal muito cansado. Não gostava ainda porque Mister Scottfield fizera aquilo com Papai...".2 O pai do protagonista havia discutido com um dos diretores da fábrica e, por isso, acabou sendo demitido, desencadeando um período de muitas dificuldades para a família. Toda essa angústia, porém, foi minimizada após seu pai conseguir um emprego na Fábrica Santo Aleixo, no município de Magé/RJ.

No contexto da obra, em particular, esta outra fábrica configurou-se como uma espécie de "porto seguro" para a família de Zezé, sendo, inclusive, valorizada a beleza do lugar onde ela estava localizada, com "rios de verdade" e "grandes árvores". O pai de Zezé era gerente na fábrica e ocupava, portanto, lugar preponderante na hierarquia sócio profissional. Tal diferenciação podia se constituir em fator gerador de diferenciações e concorrências internas ao grupo. Ainda assim, essa peculiar representação da Fábrica Santo Aleixo se aproxima (e muito) de diversas outras caracterizações construídas por meio da memória operária e de publicações locais, que passaremos a analisar adiante.

A primeira delas refere-se ao livro "Magé durante o Segundo Império e os primeiros tempos da República: a história de uma abnegada mulher", ${ }^{3}$ que conta a trajetória de Francisca D’Azevedo Paiva, poetisa, filha do capitão Gabriel de Azevedo Maia Lage, fazendeiro e chefe político local. Após um longo período de fausto e riqueza em sua família, "Chiquinha", como era conhecida a protagonis-

\footnotetext{
VASCONCELOS, José Mauro de. Meu pé de laranja lima. São Paulo: Melhoramentos, 1975. p. $187-188$.

VASCONCELOS, op. cit., p.63-64.

3 FERNANDES, Antônio de Paiva. Magé durante o Segundo Império e os primeiros tempos da República: a história de uma abnegada mulher. Rio de Janeiro: [s.n.], 1962.
} 
ta, passou a enfrentar diversos dissabores, motivados pela dificuldade financeira. ${ }^{4}$ Francisca teve que sair do convívio com o pai, na fazenda, para acompanhar o marido, José Alexandre, recém-contratado pela Fábrica de Tecidos Santo Aleixo. Mais tarde, uma de suas filhas, Zoraida, casou-se com um pequeno comerciante local, Emygdio Fernandes, um dos alvos da primeira mobilização operária de que se tem notícia na região: a "Greve do Pano". 5

Santo Aleixo sempre fora habitado por gente pacata e de costumes morigerados. Centro essencialmente fabril, pois não havia pessoas afortunadas, nem tampouco a chamada classe burguesa, tão odiada pelos que professam o comunismo. Comerciantes e operários viviam em perfeita harmonia, um dependendo do outro. Mas aquela vida boa e pacata, fora quebrada com o advento do regime comunista da Rússia. Para ali convergiam os chamados delegados dos operários, que outra coisa não eram senão meros agitadores. Promoviam comícios de rua, e nas pregações revolucionárias pregavam o amor livre, a dissolução da família e a divisão de latifúndios. [...] Ao cair da tarde, enorme massa se postava diante da agência postal, na ânsia de adquirir números dos jornais abertamente comunistas [...]. E naquele dia aprazado, os operários a um sinal convencionado [...] pararam as máquinas e entraram a praticar desatinos. O plano era por demais diabólico [...]. Instalaram o "Soviet" local, e em substituição à bandeira brasileira, hastearam a bandeira vermelha, com o dístico: "Viva Lenine". A seguir, os amotinados saíram em delírio pelas ruas precedidos pela Banda de Música, entoando a Internacional de Moscou. ${ }^{6}$

Para Antônio de Paiva Fernandes, autor da obra, esse movimento foi um "plano diabólico de amotinados", sem, no entanto, deixar de descrevê-lo como fabuloso, mesmo que noutra perspectiva. Publicada em 1962, a obra deste escritor mageense é permeada por uma forte posição anticomunista, típica da época em que foi concebida, mas que, ao mesmo tempo, apresenta a "Greve do Pano" de forma bastante apoteótica. Nota-se que seu discurso realça Santo Aleixo como um lugar "pacato e morigerado", onde patrões e operários viviam em "perfeita harmonia", harmonia essa quebrada única e exclusivamente pelos "agitadores comunistas", aqueles que "quebram" o contrato, segundo ele, estabelecido.

Outra representação interessante foi uma crônica publicada em 1963, numa revista comemorativa aos cinquenta anos de fundação do Guarany Futebol Clube, entidade mantida pela Fábrica Santo Aleixo. Organizada pela diretoria do clube, a

4 A referida obra atribui o declínio agrícola do município de Magé, no final do século XIX, aos reflexos da abolição da escravatura e ao episódio conhecido como "Horrores de Magé", no contexto da Revolta da Armada, em 1893-94, quando contingentes da Marinha se opuseram ao governo do Marechal Floriano Peixoto, que se recusou a convocar eleições após a renúncia do Marechal Deodoro da Fonseca. Sendo Magé ponto estratégico e cidade bem abastecida de víveres, ali se estabeleceram os marinheiros revoltosos, em 1893, tendo, inclusive, se apropriado da receita da Câmara Municipal e também formado "batalhões patrióticos" com moradores do município. Em seguida, tropas governistas desembarcaram no Porto Estrela e partiram para invadir a cidade, sendo registrados casos de estupro, roubos, assassinatos, saques e incêndios sob a responsabilidade da tropa florianista. Toda essa situação ocorrida em Magé foi registrada, à época, em uma série de reportagens realizadas pelo Jornal do Brasil, sob o título "Horrores de Magé", como acabou sendo conhecido o episódio. Para a família de Chiquinha, a invasão da cidade também gerou problemas, sobretudo financeiros, dando início ao período de "dissabores" abordado por Antônio de Paiva Fernandes em sua obra.

5 A greve de 1918 foi assim denominada pelos santoaleixenses mais antigos, conforme entrevistas com os ex-operários Waldomiro Pinto Carneiro e Benedito Queiroz Vieira, hoje falecidos, realizadas pelo Grupo Centenário, por ocasião da comemoração dos cem anos de criação do distrito de Santo Aleixo, em 1992. Acervo de Ademir Calixto Oliveira. A greve também foi noticiada por jornais do Rio de Janeiro. Cf.: A Noite, 22 de novembro de 1918, p.3.

6 FERNANDES, op. cit., p. 54-57. 
revista trazia na matéria, intitulada "O Tradicional Guarany x Andorinhas", a mística que envolvia o clássico entre os dois times operários, sendo este último mantido pela Fábrica Andorinhas, também localizada no distrito de Santo Aleixo.

Num pequeno ponto do território mageense, situa-se Santo Aleixo. [...] Suas paisagens, muitas das quais ainda desconhecidas, proporcionam inspirações de gratidão ao nosso Senhor, por ter com sua Divina Graça, sido tão generoso em nos oferecer tão simpático e atraente lugarejo. E tudo isso, nos dá um aspecto de que seu povo vive numa verdadeira paz entre seus irmãos. No entanto, existe um dia em que tal paz e a comunhão de verdadeira amizade entre seus filhos é ligeiramente estremecida. Dizemos ligeiramente pelo fato de tal estremecimento não atingir a solidez em que foi firmado o alicerce desta amizade. Sim, meus amigos, quando o Campeonato Mageense de Futebol assinala em sua tabela o clássico de maior envergadura municipal: Guarany Futebol Clube $x$ Andorinhas Futebol Clube, os habitantes desta tão exaltada cidade experimentam modificações sensíveis em sua personalidade, a qual é sobreposta pelo sentimento de amor pelas cores do seu clube. Uma semana antes do jogo, os comentários são inúmeros [...] Os de cima evitam mesmo de vir cá embaixo. Os daqui, igualmente, se sentem desambientados em ir lá em cima. E é nesse clima de verdadeira tensão que chega o dia em que no campo os times e as torcidas se defrontam [...] Após o jogo, ou melhor, passado então mais ou menos uma semana, as torcidas vão assumindo novamente a sua forma. E a calma volta a reinar em Santo Aleixo. Seus filhos vão naturalmente voltando a um mesmo convívio. As hostilidades desaparecem, dando lugar a um outro sentimento de maior envergadura: o do trabalho e da ajuda desinteressada ao próximo, seja do lado de lá ou do lado de cá.?

Similitudes são observadas nesses discursos. Por exemplo, quando Santo Aleixo é apresentado como um lugar de "paz, amizade e comunhão", onde somente situações extraordinárias, normalmente movidas por paixões fugazes, conseguem "ligeiramente" estremecê-lo. No primeiro deles está a paixão comunista; no seguinte, a paixão pelo time operário.

Essas representações discursivas encontram eco nos depoimentos de alguns operários, indicando a presença de um forte fator de coesão entre os trabalhadores têxteis do local, como é possível perceber nas falas dos tecelões Jorge e Maria Oneida, respectivamente:

[...] Santo Aleixo era um lugar animado, um lugar que gerava muito emprego. As fábricas geravam muito emprego na época. [...] Tudo ali em Santo Aleixo e Andorinhas girava em torno da economia das duas fábricas né. Era emprego para as crianças, assim... Entrava com quatorze anos e trabalha até aposentar... Muita gente em Santo Aleixo e Andorinhas aposentou novo porque entrou trabalhando ali aos quatorze anos. [...] As pessoas vinham de Magé trabalhar, de outros lugares... [...] Havia-se muito respeito, era muito bom. Você não via ninguém saindo, falando bandalheira no meio da rua. Você ia num clube, num baile, era muito respeitado, ninguém te faltava com respeito. Era uma época muito boa $[\ldots]{ }^{8}$

[...] Tinha o cinema, que tinha a primeira seção às 6 horas, e a segunda às 8 horas. Tinha também o refeitório do lado, onde fazia tarde dançante. Então a gente ia pra tarde dançante, e depois a gente ia pro cinema.

7 GUARANY FUTEBOL CLUBE. Revista comemorativa do jubileu de ouro (1913/1963). Santo Aleixo, Magé/RJ, 1963, p. 15 e 17, passim.

8 Entrevista com o ex-operário Jorge Carloto Lima, concedida a Joana Lima Figueiredo, em 22de março de 2008. 
No domingo e qualquer feriado que dava, que tivesse um filme bom, a gente assistia. A época era muito boa [...].9

Percebe-se, ainda, que a centralidade do trabalho fabril fundamenta as lembranças e, por conseguinte, a identidade coletiva de toda uma geração, cuja vivência de uma época aparece como "tempo áureo", que não existe mais, em que havia solidariedade, respeito, amor e no qual as pessoas "trabalhavam muito".

Raros são os depoimentos que caracterizam a Fábrica Santo Aleixo como na metáfora do "dragão que todo dia comia gente e de noite vomitava o pessoal muito cansado", tal como o menino Zezé definiu a Companhia Progresso Industrial do Brasil, em Bangu. Via de regra, as memórias que caracterizam queixa e conflito são atribuídas a algum elemento externo, "fora de Santo Aleixo", como o comunismo, já exemplificado anteriormente.

Da mesma forma, o tempo áureo da localidade coincide com o tempo em que suas indústrias funcionavam a pleno vapor. Assim, o trabalho nas fábricas representou a manutenção do funcionamento do "órgão gerador da própria vida do lugar”. O mito fundador desta época áurea, formada por operários-moradores de Santo Aleixo, é, sem dúvida, a chegada ao local de dois empresários que protagonizaram a trama responsável pela transformação do cenário, então marcado pelo refluxo econômico e social decorrente da crise que se desenrolara nos anos anteriores. Trata-se dos empresários Hermann Mattheis e Othon Lynch Bezerra de Mello, que adquiriram, respectivamente, as fábricas Andorinhas, em 1935, e Santo Aleixo, no ano de 1941, ambas no distrito. Esse marco, fortemente presente na memória coletiva, aparece nas falas dos operários Jorge e Maria Oneida, citadas acima. Eles fazem menção ao "refeitório ao lado da fábrica”, construído pela Companhia Bezerra de Mello; e às "pessoas [que] vinham de Magé e de outros lugares trabalhar nas fábricas", no período de intensa migração para Santo Aleixo, que ocorreu no contexto pós-Segunda Guerra Mundial.

No entanto, não só de consenso vive a memória operária local, como tem sido evidenciado em estudos acadêmicos produzidos nas últimas décadas, ${ }^{10}$ grande

9 Entrevista com a ex-operária Maria Oneida Péclat, concedida a Juçara Mello, em 18 de janeiro de 2007.

10 Cf.: OLIVEIRA, Sônia Maria Gonzaga de. Montanhas de Pano: fábrica e vila operária em Santo Aleixo. Dissertação (Mestrado em Antropologia Social). Universidade Federal do Rio de Janeiro - UFRJ. Rio de Janeiro: Museu Nacional, 1992; PEREIRA, Aline Fernandes. A Fábrica Santo Aleixo: a importância de uma indústria têxtil como exemplo de trabalho manufatureiro livre em uma sociedade escravista. Dissertação (Mestrado em História Social). Universidade Severino Sombra. Vassouras, 2006; FIGUEIREDO, Joana Lima. Fábrica Santo Aleixo: Magé, Arte e Patrimônio da Industrialização (1847-1979). Dissertação (Mestrado em Ciência da Arte). Universidade Federal Fluminense - UFF. Niterói, 2008; MELLO, Juçara da Silva Barbosa de. Fios da Rede: industrial e trabalhadores na criação e expansão de um grupo empresarial (1920-1949). Tese (Doutorado em História Social da Cultura). Pontifícia Universidade Católica do Rio de Janeiro - PUCRio. Rio de Janeiro, 2012; MELLO, Juçara da Silva Barbosa de. Identidade, memória e história em Santo Aleixo: aspectos do cotidiano operário na construção de uma cultura fabril. Dissertação (Mestrado em História Social). Faculdade de Formação de Professores - UERJ. São Gonçalo, 2008; MELLO, Juçara da Silva Barbosa de. O compasso da vida no ritmo da fábrica: identidade e memória do cotidiano operário em Santo Aleixo. Monografia (Graduação em História). Faculdade de Formação de Professores - UERJ. São Gonçalo, 2005; LAGE, Sofia Martins. A Indústria Têxtil em Santo Aleixo: Processo de Industrialização em Santo Aleixo e seus impactos nas transformações do espaço urbano. Monografia (Graduação em Geografia). Faculdade de Formação de Professores - UERJ. São Gonçalo, 2007; LOPES, Isabela Pereira. Sonhos em Retalhos: a creche da Fábrica Andorinhas em Santo Aleixo-RJ (1946-1970). Monografia (Graduação em Educação). Universidade Federal Fluminense - UFF. Niterói, 2006; LOURENÇO, Roberta da Silva. Moscou brasileira: o Sindicato dos Trabalhadores das Indústrias de Fiação e Tecelagem de Santo Aleixo. Monografia (Graduação em História). Universidade Salgado de Oliveira - UNIVERSO. São Gonçalo, 2005; MARINS, Geilson de Sena. Fábrica de Santo Aleixo: fundação em 1848 e memória da vila operária no século XX. Monografia (Graduação em História). Universidade Federal Fluminense. Niterói, 2006; RIBEIRO, Felipe Augusto dos Santos. Astério dos Santos, o operário: processo de acumulação política, memória e 
parte deles lançando mão da História Oral, entrevistando antigos operários. Tudo isso sem falar nos esforços de grupos locais para a valorização de sua história, como ocorreu durante as comemorações do centenário do distrito de Santo Aleixo, em 1992, quando membros do Grupo Centenário realizaram uma série de entrevistas com antigos moradores, a fim de perpetuar a memória do "Paraíso Verde"."

Algumas dessas entrevistas, mesmo as que valorizam o consenso, permitem análises capazes de relativizar o mito do tempo áureo. Como é possível observar, mais uma vez, na fala da tecelã Maria Oneida:

A gente perdia a mocidade da gente, a juventude, a adolescência [...] era uma escravidão, uma escravidão mesmo! Mesmo assim eu sou muito grata a essa fábrica, porque se não fosse ela... Eu tinha pouca experiência, pouco estudo. Casa de família? Ninguém aqui podia pagar empregada. Sair pra fora? De que jeito? Então pra mim, a fábrica foi uma mãe, uma mãe severa, mas foi uma mãe!

Eu tinha muito medo dos comunistas, porque eles eram revoltados, eram baderneiros e a gente que não é né... [...] Eu nunca me meti nisso não, eu ficava na minha. Às vezes eles estavam até certos, mas às vezes eles se excediam um pouco... [... $]^{12}$

Apesar disso, percebemos que há certa tendência em alguns dos estudos sobre as relações sociais construídas em Santo Aleixo a partir do desenvolvimento das fábricas de tecidos em apresentar uma espécie de dualidade, mesmo que adotando um olhar crítico sobre as representações de "harmonia social", citadas anteriormente: de um lado, aborda-se uma visão de consenso no cotidiano operário como fruto quase que exclusivo da ação das fábricas e de suas políticas sociais, muitas vezes restringindo-a ao âmbito local, ambiente considerado favorável às formas de desistência e desmobilização entre os tecelões diante da dominação industrial na esfera do trabalho e na vida fora das fábricas; de outro, caracteriza-se as questões de conflito somente a partir da militância política institucional, com a ação dos sindicatos e do Partido Comunista do Brasil (PCB), esta sempre alçada à esfera nacional e internacional, consolidando, assim, uma noção idealizada de resistência e mobilização operária. ${ }^{13}$

identidade dos trabalhadores têxteis de Santo Aleixo (1941-1964). Monografia (Graduação em História). Faculdade de Formação de Professores - UERJ. São Gonçalo, 2006; RIBEIRO, Felipe Augusto dos Santos. Operários à tribuna: vereadores comunistas e trabalhadores têxteis de Magé (1951-1964). Dissertação (Mestrado em História Social). Faculdade de Formação de Professores - UERJ. São Gonçalo, 2009, 270f; e SOARES, Carla Rosa. Magé: memória e história de uma comunidade fabril. Monografia (Graduação em História). Universidade Salgado de Oliveira - UNIVERSO. São Gonçalo, 2006. Grande parte desses trabalhos apresenta abordagens que privilegiam as "memórias de consenso", em detrimento das "memórias de conflito", construindo uma clivagem, a nosso ver, perigosa. No presente artigo, seguindo a trajetória de pesquisa dos autores, buscaremos analisar essas memórias em conjunto e suas implicações para além do local de trabalho.

11 Este foi o cognome utilizado pelo Grupo Centenário para caracterizar Santo Aleixo, em 1992. Localizado no sopé da Serra dos Órgãos, banhado por diversos rios e notabilizado por belas cachoeiras, buscou-se apontar o potencial turístico do distrito como grande oportunidade de desenvolvimento econômico local, sobretudo após o fechamento das fábricas de tecidos. Ressalta-se que a "beleza do lugar" também foi exaltada em Meu Pé de Laranja Lima.

12 Entrevista com a ex-operária Maria Oneida Péclat, op. cit.

13 Esta questão também foi enfrentada por José Sérgio Leite Lopes, quando abordou a questão da "grande indústria na pequena cidade", diagnosticando visões acadêmicas consolidadas no atacado que apresentam certo padrão idealizado de relações industriais, tomado da sociologia industrial americana e europeia, que minimizam as formas de resistência operária, apontando para o consenso, mesmo quando há conflito. Cf.: LOPES, José Sérgio Leite. Sobre os trabalhadores da grande indústria na pequena cidade: crítica e resgate da ‘Crise do Brasil Arcaico'. In: LOPES, José Sérgio Leite (Org.). Cultura \& identidade operária: aspectos da cultura da classe trabalhadora. Rio de Janeiro: Marco Zero, UFRJ, 1987, p.147-170. 
Essas implicações nos remetem às reflexões apresentadas por Mike Savage sobre os trabalhadores e suas redes de contato na formação de classe, ${ }^{14}$ nas quais nos interessa, especificamente, a possibilidade que então se apresenta para a superação do antagonismo social x político. Segundo o autor, tal antagonismo é um equívoco que persiste em diversos estudos sobre trabalho e trabalhadores, a que chama de "erro do isso ou aquilo". Como proposta, Savage sugere uma "análise das redes de contato", explorando a mediação entre estrutura e ação (em si/para si):

Parece possível admitir que não há relação de determinação entre o mundo do dia-a-dia, as lutas práticas para enfrentar a incerteza [insegurança estrutural operária] e o mundo das agremiações e instituições políticas formais que se dedicam a mobilizar e generalizar aquelas ações em movimentos sociais e forças eleitorais. Não obstante, não devemos presumir que lideranças e instituições políticas mobilizem as pessoas de maneira livre e sem constrangimentos. Os tipos de embates práticos cotidianos nos quais as pessoas se engajam para fazer face à insegurança estrutural formam um sólido leito disponível a campanhas partidárias. Sem dúvida, há uma considerável autonomia para os partidos reelaborarem variadas espécies de questões cotidianas e práticas em movimentos e ideologias políticas coerentes, embora os chamamentos mais eficazes mobilizem as pessoas em torno de questões presentes no seu dia-a-dia. ${ }^{15}$

O autor destaca que, para demonstrar o quanto tais estratégias são passíveis de ser generalizadas, devemos antes examinar os contextos em que as vidas operárias são vividas: "tempo e espaço não como pano de fundo, mas como parte intrínseca do processo". ${ }^{16}$ Ao mesmo tempo, Savage salienta que a historiografia ainda carece de muitos exemplos adicionais a respeito de como essas redes de contato podem ser objeto de estudo para a História do Trabalho.

No caso de Santo Aleixo, objeto do presente artigo, essa dicotomia normalmente relaciona o "social" à ideia de uma "comunidade" construída a partir dos benefícios oferecidos pela fábrica (patrocinando atividades religiosas, esportivas e carnavalescas), mas também reforçada pela relação de harmonia entre patrões e empregados, ao passo que o "político" é visto como algo "fora da ordem", opondo-se e comprometendo a ideia de comunidade.

Entretanto, ao rompermos a barreira de uma visão dicotômica, relevantes intercessões se revelam. Isso ocorre em análises de caricaturas desses dois mundos, que vão desde militantes comunistas que caem no samba e lideram blocos patrocinados pela fábrica até tecelões evangélicos que ingressam no PCB sem abandonar a devoção religiosa. A ênfase sobre essa mediação, sem deixar de considerar que tempo e espaço são "parte intrínseca do processo", possibilitou a percepção do quanto o contexto específico do distrito de Santo Aleixo foi capaz de intensificar as redes entre os trabalhadores locais.

Nesse sentido, o presente artigo pretende contribuir com os debates suscitados por Savage, a partir do caso da Fábrica Santo Aleixo, particularmente durante a Segunda Guerra Mundial (1939-1945). A escolha desse contexto tornou-se

14 SAVAGE, Mike. Classe e história do trabalho. In: BATALHA, Cláudio Henrique de Moraes; SILVA, Fernando Teixeira da; FORTES, Alexandre (Org.). Culturas de classe: identidades e diversidade na formação do operariado. Campinas, SP: Universidade Estadual de Campinas (UNICAMP), 2004. p.25-48; e LOPES, José Sérgio Leite. Espaço, redes e formação de classe. Revista Mundos do Trabalho. v.3. n.5. jan.-jun./2011, p.06-33.

15 SAVAGE, op. cit., 2004, p. 39.

16 Ibidem, p. 44. 
inevitável devido às diversas implicações que ele provocou na formação da classe trabalhadora local e na consolidação de uma cultura fabril. No período, o distrito vivenciou inúmeras transformações, diretamente ligadas à Fábrica Santo Aleixo e seus trabalhadores: [1] a fundação do sindicato têxtil, em 1941, e sua escola sindical, em 1943, ancorado à Consolidação das Leis do Trabalho (CLT); [2] a compra da fábrica pelo empresário Bezerra de Mello, em 1941, a difusão de uma forte política social (com a construção da Vila Operária, entre outras ações), além de diversos incentivos fiscais obtidos pela empresa no chamado "esforço de guerra"; [3] a efervescência comunista pós-1940, com várias campanhas ligadas ao contexto do conflito mundial, consolidando a proeminência do PCB na região até 1964; [4] a criação do Círculo Operário Católico no distrito, em 1945; e [5] o fim do Estado Novo e a atuação dos recém-criados partidos políticos, justamente no período em que o trabalhador tornava-se eleitor. ${ }^{17}$

\section{Tempo, espaço e lugar na construção de uma cultura operária fabril}

Uma análise das experiências vivenciadas pelos operários de Santo Aleixo, realizada à luz das reflexões de Mike Savage acerca das relações entre "espaço, tempo e lugar", possibilitou que novos e diferentes elementos fossem considerados no conjunto das determinações e possibilidades que as envolveram. Uma especial atenção à história local propiciou a percepção de como o cotidiano de toda uma geração de trabalhadores esteve fortemente marcado pelas relações existentes em torno do trabalho. Suas histórias de vida apresentam-se pontilhadas por descrições da formação do lugar, nas quais são feitas menções "ao tempo" das ampliações das fábricas têxteis, da inauguração dos cinemas, dos clubes sociais, das igrejas, das escolas, bem como do sindicato, onde são revividas comemorações anuais que deixam entrever as especificidades das relações sociais que "faziam o lugar".

Ao mesmo tempo, esse olhar para o "lugar" apresenta os trabalhadores interagindo dinâmica e efetivamente nesse espaço social, construído no bojo de relações hierárquicas, nas quais a "insegurança estrutural" que marca suas vidas, longe de resultar em imobilidade e passividade, mobiliza a criação de redes de solidariedade que se articulam tanto no espaço de trabalho quanto no da vizinhança e no do lazer. Enfim, ao expandir o foco das relações de trabalho para as demais áreas do conjunto da vida social desses trabalhadores, encontramos uma referência que exemplifica em grande medida a afirmação de Savage acerca do processo de formação da classe, um "processo espacial, em que identidades locais e identidades de classe se podem fundir e combinar". ${ }^{18}$ Essa perspectiva de análise sugere a compreensão de uma necessária consideração da vida operária como um todo, inclusive das relações internas de suas diversas esferas; e externas, quando - na interação com seus diversos "outros" - as identidades de classe e locais foram sendo delineadas numa relação de influências recíprocas.

17 Destaca-se que o cognome "Moscouzinho" é bastante recorrente em matérias jornalísticas e em entrevistas com antigos operários, devido às expressivas votações do PCB em Santo Aleixo nas eleições pós-Segunda Guerra. Entre 1947 e 1964, por exemplo, o partido elegeu vereadores, por meio de legendas emprestadas, em todos os pleitos municipais. Ao todo, foram onze comunistas eleitos, sendo a maioria ex-tecelões do distrito.

18 SAVAGE, op. cit., 2004, p. 41. 
Em Santo Aleixo, a situação de fábrica com vila operária, combinada ao isolamento, resultante de sua configuração geográfica, propiciaram a concretização de experiências coletivas geradoras de um peculiar processo de sedimentação das identidades sociais. A especificidade dessas experiências foi potencializada pelo próprio modo como se caracterizou o processo de adensamento da população. O lugar tornou-se um verdadeiro polo de atração de famílias oriundas de regiões vizinhas. Houve, inicialmente, uma migração interna, quando a população, outrora ocupada com atividades agrícolas, passou a se concentrar ao redor dessas fábricas. Posteriormente, houve migrações externas, intermunicipais e interestaduais, aumentando significativamente o número de habitantes.

Eu sou do Sana, distrito de Casimiro de Abreu. Vim pra aqui [Santo Aleixo] com 6 ou 7 anos [na década de 1940]... A primeira a morar na casa da fábrica foi minha irmã que casou. Aí depois nós chegamos. Eu, minha irmã e meus dois irmãos. Primeiro nós fomos morar na casa de uma família. Nós viemos pra cá por causa da fábrica, porque já não dava mais pra trabalhar na roça, a vida na roça tava muito difícil. ${ }^{19}$

Esse intenso movimento migratório em direção ao distrito de Santo Aleixo ligase ao contexto de incremento das atividades industriais no Brasil. Como é sabido, a década de 1930 foi marcada por um aumento dessas atividades no país. Nesse período, a legislação social que vinha sendo objeto de lutas em anos anteriores passou a ser efetivamente elaborada e implementada, traduzindo-se em significativos benefícios para o trabalhador industrial, sobretudo quando posto numa relação com o trabalhador rural. Tais medidas, conjugadas aos melhoramentos proporcionados pela abertura das estradas no município de Magé, possibilitaram o surgimento e o progressivo crescimento da ocupação em torno da Fábrica Pau Grande (também em Magé) e da área circunvizinha às Fábricas Santo Aleixo e Andorinhas.

A aquisição da Fábrica Santo Aleixo pelos Bezerra de Mello ocorreu nesse contexto, revelando-se como parte de uma bem calculada estratégia empresarial. A escritura de Constituição da Companhia Fiação e Tecelagem Bezerra de Mello, registrada num cartório do Rio de Janeiro, em 27 de janeiro de 1941, descreve o processo de aquisição da fábrica que pertencia à Companhia Agrícola e Industrial Magalhães, posteriormente rebatizada de "Fábrica Esther", numa homenagem a uma das filhas do empresário e patriarca pernambucano. ${ }^{20}$

Uma série de mudanças foi empreendida na Fábrica Esther, tanto no prédio da produção quanto em seus arredores. A produção foi iniciada com 500 teares, voltados para a fabricação de brins e zefires, que no contexto da guerra era de larga aceitação nos mercados internos e sobretudo nos externos. Seguindo o modelo já adotado nas fábricas de Pernambuco, ${ }^{21}$ o Grupo Bezerra de Mello passou a

19 Entrevista com Maria Oneida Peclat, concedida a Juçara Mello, em 18 de agosto de 2007.

20 Othon Bezerra de Mello pode ser considerado um típico patriarca pernambucano. A importância atribuída à família se expressa por meio de muitas de suas atitudes e ações; uma delas está no fato de que, com exceção da que recebia seu nome em Pernambuco, a "Coronel Othon", todas as suas demais fábricas de tecidos foram nomeadas homenageando esposa e filhas: a Maria Amália e Anita em Pernambuco, em homenagem, respectivamente, à esposa Maria Amália e à filha Ana; a Esther em Santo Aleixo, a também Maria Amália em Minas Gerais e a Carmem em Alagoas. Todos os oito filhos homens foram preparados para administrar os empreendimentos da família.

21 Em matéria que ocupou uma página inteira do jornal Correio do Ceará, em março de 1942, foram descritos todos os benefícios sociais oferecidos nas fábricas do Grupo Bezerra de Mello em Pernambuco, e no qual consta que estudos especiais estavam sendo feitos para que na recém-adquirida Fábrica Esther fossem "instituídos os mesmos benefícios sociais de que gozam as demais organizações do Cotonifício Othon Bezerra de Mello, considerado o melhor do Brasil”. In: Correio do Ceará, 02 de março de 1942. 
investir na criação de uma infraestrutura que contava com vila operária abastecida de água, luz elétrica e esgoto; construiu escola, igreja e praça. Assim, ao mesmo tempo em que era garantida a permanência e a formação da força de trabalho, também procurava estender o controle exercido no chão da fábrica a todas as esferas da vida social dos trabalhadores. Tais mecanismos foram progressivamente desenvolvidos e institucionalizados, manifestando-se de forma direta no dia a dia dos operários e de seus familiares: na saúde, mediante o fornecimento de assistência médico-farmacêutica; na religião, com a edificação de igrejas para o atendimento espiritual; e no lazer, investindo na construção de praças e de um cinema, patrocinando clubes esportivos, blocos de carnaval e bandas de música, e criando associações operárias recreativas, que promoviam bailes, piqueniques, passeios e jogos de futebol.

Todas essas mudanças contribuíram para a construção de uma memória na qual a administração de Bezerra de Mello é concebida como marco fundador de um "tempo áureo". Contudo, sem que se contradiga tal memória, o processo de constituição de uma situação sociocultural específica em Santo Aleixo, marcada pelo trabalho fabril, teve início em período bem anterior ao da chegada dos Bezerra de Mello. A instalação de fábricas têxteis no lugar remonta a meados do século XIX, momento em que se inicia um longo processo de constituição de uma tradição fabril, não fundada, mas redimensionada a partir das mudanças estruturais promovidas pela nova administração.

A modernização das instalações fabris e a criação de infraestrutura social para os operários são ações que refletem o discurso do empresário Bezerra de Mello, marcado, desde meados da década de 1920, pela defesa do progresso do país pela via industrial. Para o empresário, "as fábricas, além de contribuírem extraordinariamente para o aumento da riqueza pública”, beneficiam os operários "com assistência médica e dentária, ensino em aulas noturnas, associações recreativas e de beneficência e salários duas a três vezes maiores do que o que lhes paga a agricultura". ${ }^{22}$

O discurso apoteótico e apologético do empresário revela explicita e implicitamente os interesses nele expressos. Contudo, não é possível desconsiderar o fato de que o emprego associado à moradia — num momento caracterizado pela carência de habitações consideradas dignas - , somado a toda a infraestrutura oferecida pela fábrica em locais isolados dos grandes centros urbanos, tornaram o lugar um verdadeiro polo de atração de famílias camponesas oriundas de regiões vizinhas.

Tudo isso contribuiu para um relativo consenso em torno da imagem do "bom patrão", do "velho Othon", como grande responsável por todas as benfeitorias voltadas aos operários, gerando uma espécie de pacto de reciprocidade, no qual os trabalhadores deveriam responder com lealdade e dedicação ao trabalho. As ações de Bezerra de Mello à frente de seu grupo empresarial parecem ter sido norteadas por um discurso cujo eixo estaria firmado na existência, no seu próprio dizer, de um "espírito familiar" envolvendo suas empresas. A declaração de que os filhos se confundiam com operários ${ }^{23}$ traduz bem o sentido dessa representação, que trazia, ainda, o peso de uma retórica que buscava, consciente ou inconscientemente, uma identificação com a ideia — defendida pelo Estado brasileiro — da paz social fundamentada numa harmonização entre as classes.

22 MELLO, Othon L. Bezerra. A Evolução da Indústria de Tecidos de Algodão em Pernambuco, op. cit., p. 56.

23 O Jornal, 05 de fevereiro de 1930. 
As relações sociais engendradas a partir da centralidade do trabalho fabril em Santo Aleixo foram amadurecidas e vivenciadas intensamente com as mudanças empreendidas pela nova administração. Mudanças que causaram enorme impacto no cotidiano de uma geração de trabalhadores, cuja memória, ainda hoje, guarda lembranças que sustentam laços de compartilhamento e vínculos de pertencimento à cultura fabril construída nesse tempo e lugar.

Contudo, a identificação desses trabalhadores com o modo de vida e de trabalho desse tempo considerado "áureo" não os torna meros depositários de uma ideologia. É certo que não é possível ignorar a presença dos elementos de dominação e subordinação marcando as relações sociais e de produção desses operários, mas é preciso considerar que os aspectos presentes na cultura desses trabalhadores refletem vivências bem mais complexas. A multiplicidade de sua experiência social, percebida no espaço do trabalho, sim, mas também nas relações familiares, de vizinhança e no lazer, atuou diretamente em suas formas de interagir com a mudança, de tecer dissenções e afinidades.

Isso é o que parece ocorrer nos casos em que a manutenção do princípio patriarcal da família camponesa, no ambiente da produção fabril, era favorecida pela moral familiar apregoada pela empresa, contribuindo para o consenso dos trabalhadores em torno de sua ideologia. Do ponto de vista dos trabalhadores, a disseminação de uma moral familiar pelas empresas, para além de representar dominação por meio de um mecanismo de controle e repressão, significou também um canal aberto para a constante reivindicação da contrapartida do empresário no jogo de compromissos e lealdades trazidos pela noção de família, por ele mesmo difundida.

Esse "pacto de reciprocidade" sustentou-se por concessões de ambas as partes. Para além dos interesses objetivos dos trabalhadores, dos quais dependiam para sua subsistência material, estavam igualmente em jogo crenças, costumes e tradições. A dignidade do trabalho, por exemplo, estava entre os valores que impulsionavam os trabalhadores a contribuir com o crescimento acelerado da produção da Fábrica Santo Aleixo (Esther) nos anos da guerra. Esse crescimento gerou um rápido retorno financeiro do investimento feito em sua compra, antes mesmo de 1944, quando o setor têxtil é incluído no conjunto de outras indústrias consideradas de "interesse nacional”. Esse dado aparece na fala do filho caçula do patriarca, o empresário Álvaro Bezerra de Mello: "papai tinha orgulho em dizer que em apenas quatro meses pagou a fábrica de Santo Aleixo, sem precisar investir um centavo sequer, apenas com a produção da própria fábrica".

Não por acaso, o período do chamado esforço de guerra, marcado pela suspensão dos direitos trabalhistas e da exigência sobrecomum do trabalho dos operários, foi perpassado pelo incremento dos benefícios sociais oferecidos aos trabalhadores. A decisão pela construção de uma nova vila operária ocorre nesse contexto, gerando grande mobilização na comunidade operária. ${ }^{24}$

Outra ação da fábrica nesse período, geradora de grande mobilização, foi o forte apoio ao Bloco de Penas “Tribo Guarany”. A fábrica contribuía com as atividades do bloco de diferentes maneiras. Uma delas era dispensando os operários de algum tempo do trabalho para que pudessem ensaiar, e de acordo com o operário Paulo Lopes, "tinha um gerente camarada que mandava a gente tingir as coisas na

24 Convém mencionar que a nova vila operária em Santo Aleixo foi projetada no ano de 1943 e inaugurada em 1946. A organização espacial das casas foi projetada no formato de um "V", como alusão à vitória dos aliados na guerra. Esse dado é recorrente na memória dos antigos operários que o veem como uma homenagem da fábrica aos brasileiros que lutaram nos campos da Europa. 
fábrica, as penas dos blocos e ajudava com tecidos para as fantasias". 25 O caráter emblemático dessas ações se potencializa quando é posto em evidência o fato de que Paulo Lopes - organizador e líder dessa agremiação carnavalesca - participava ativamente na militância do Partido Comunista e em ações de resistência organizadas pelo sindicato local, denotando o quanto a multiplicidade da experiência social deste e do conjunto dos operários neste tempo e lugar específicos exerceu influência sobre as formas de conflito e sobre a mobilização política. No ano de 1945, a título de exemplo, o enredo de outro grupo carnavalesco local também composto por operários - foi “A cobra fumando", em alusão à atuação vitoriosa da Força Aérea Brasileira na Segunda Guerra Mundial:

\author{
Os bravos soldados brasileiros \\ que vem demonstrando seu valor \\ nos campos da velha Europa \\ dizendo que a cobra fumou. \\ Essa jornada gloriosa que todo mundo já sabe. \\ Enche de orgulho os brasileiros, o valor de nossa FAB.
}

A atuação política desses trabalhadores deve, portanto, ser compreendida em seu caráter complexo e plural, pois imbricada no universo fabril: no cotidiano de trabalho e no convívio com a comunidade, tornando-a impregnada por uma cultura própria. O mesmo operário que, devido à atuação em atividades partidário-sindicais, foi alvo de forte repressão, era constantemente mencionado pelas chefias como exemplo de dedicação ao trabalho, além de participar em posição de liderança de diversas atividades recreativas oferecidas pelas fábricas.

Nesse sentido, importa observar que a concepção presente na memória dos operários-moradores de Santo Aleixo, que concebem a fábrica como uma "mãe severa, mas uma mãe", se deve menos ao sucesso de uma tentativa de dominação ideológica e mais à necessidade de justificar suas próprias trajetórias, inexoravelmente marcadas pela presença da fábrica. Para lidar com a "insegurança estrutural" gerada pela dependência tanto do trabalho - de grande parte - quanto da moradia, os operários-moradores de Santo Aleixo lançaram mão de estratégias e táticas, ora articuladas em torno de redes forjadas a partir de identidades locais, ora sedimentadas nas redes - densas e de amplo alcance - construídas em torno do trabalho.

\title{
Formas de organização e lutas dos tecelões santoaleixenses
}

\footnotetext{
Salve $1^{\circ}$ de Maio, Dia do Trabalho: o proletariado de Magé, Santo Aleixo e Andorinhas unidos comemoram esta data obedecendo as diretrizes do Estado Novo, criado pelo nosso grande chefe e Dr. Getúlio Vargas. Salve as autoridades que nos honraram com suas presenças na data de hoje. Aceite nossos agradecimentos.
}

25 Entrevista com Paulo Lopes, concedida a Juçara Mello, em 03 de fevereiro de 2005. 
Ostentando uma faixa com esses dizeres, o Sindicato de Santo Aleixo realizou uma de suas primeiras celebrações ao Dia do Trabalho, em 1943. A manifestação ocorreu na Praça X de Novembro, no bairro de Andorinhas, reunindo cerca de trinta operários, formados bem em frente ao coreto da praça. Eles hasteavam a bandeira nacional, portavam instrumentos musicais de marcação e marcialidade, bem como demonstravam o caráter cívico e ordeiro da celebração. Meses mais tarde, em outubro, o sindicato já inaugurava sua sede social e uma escola de ensino primário. ${ }^{26}$

O sindicato teve origem em 1939, quando foi organizada a Associação Profissional dos Trabalhadores nas Indústrias de Fiação e Tecelagem de Magé, Santo Aleixo e Andorinhas, como filial do Sindicato de Pau Grande. Esse seria o núcleo que, após concessão da Carta Sindical do Ministério do Trabalho, deu origem ao Sindicato dos Trabalhadores das Indústrias de Fiação e Tecelagem de Santo Aleixo e Magé, fundado em 16 de março de 1941.

Inseridos inicialmente em um contexto de forte enquadramento promovido pelo Estado Novo, o sindicato tornou-se paulatinamente um importante instrumento de reivindicação e conquista do operariado santoaleixense. Seu primeiro presidente, por exemplo, Marciano Macedo de Freitas, nas palavras do comunista José Rodrigues, era "um homem de confiança da fábrica" que havia assumido o cargo "num período de ditadura". ${ }^{27}$ Vale ressaltar que essa aproximação entre indústria têxtil e Estado foi se consolidando aos poucos, tendo em vista que ela sempre demonstrou muita resistência à aplicação da legislação social difundida pelo Ministério do Trabalho. Contudo, desde a participação efetiva do Brasil na Segunda Guerra Mundial, instituiu-se o chamado "esforço de guerra", que, do ponto de vista econômico, configurou-se como um evidente estímulo à produção. ${ }^{28}$

[...] Santo Aleixo foi um dos distritos do Brasil que mais trabalharam pelo nosso esforço de guerra em prol da FEB. Os teares trepidavam dia e noite, o seu ruído varava as madrugadas. Nós nos matávamos nas horas extraordinárias para que os nossos pracinhas pudessem partir logo. Queríamos que eles fossem ajudar os nossos aliados no esmagamento, o mais rapidamente possível, da besta nazista. ${ }^{29}$

Durante o ano de 1942, ao passo que o presidente Getúlio Vargas conclamava os trabalhadores, os "soldados da produção", em pleno 1. ${ }^{\circ}$ de Maio, para um período de muito trabalho e sacrifícios, naquilo que seria denominado de "batalha da produção", o governo decretava uma série de leis ${ }^{30}$ que, respondendo às pressões das indústrias, em particular as têxteis, suspendia a vigência de diversos direitos trabalhistas. Em Magé, o chamado "esforço de guerra" logo se fez sentir quando a Fábrica Santo Aleixo aderiu à proposta governamental, comprometendo-se a fabricar o brim-marinho, tecido base para a confecção dos uniformes dos marinheiros brasileiros que iriam para o front. Na ocasião, embora passados dois meses do anúncio do governo e não tendo chegado ainda a matéria-prima, "a fábrica já tinha aumentado de um para três turnos, isenta de impostos e direitos trabalhistas... Era um blefe!", relatou José Rodrigues, que foi preso e “desterrado” de Santo Aleixo

26 "Uma escola em Magé para os filhos de trabalhadores". In: A Manhã, 02 de novembro de 1943, p. 10. A Escola Sindical $1 .^{\circ}$ de Maio, fundada em 1943 , funcionou nas dependências do Sindicato e era mantida pela entidade.

27 Entrevista concedida por José Rodrigues, ex-operário e líder comunista, a Felipe Augusto dos Santos Ribeiro, em 04 de agosto de 2006.

28 Cf.: GOMES, Angela de Castro. A invenção do trabalhismo. 3.ed. Rio de Janeiro: FGV, 2005, p. 167 e 186, passim.

29 Tribuna Popular, 13 de abril de 1946, p. 8. Entrevista concedida pelo tecelão José Pereira da Silva.

30 Decretos-lei n. ${ }^{\circ}$ 4.639, 4.869 e 4.937, outorgados, respectivamente, em agosto, outubro e novembro de 1942. 
após redigir, com outros companheiros, uma carta denunciando essa situação. Dirigida aos jornais da capital, ao ministro da justiça, ao governador e ao prefeito, a missiva foi interceptada e entregue à polícia. ${ }^{31}$

José Rodrigues dirigiu-se, então, a Petrópolis, onde se tornou dirigente do $\mathrm{PCB}$, ao passo que, em Magé, despontava paulatinamente a liderança do médico sanitarista Irun Sant'Anna, que chegou à cidade para combater a malária, mas acabou envolvendo-se na política local, sobretudo com os tecelões do município. Filiado ao PCB desde 1935, o médico começou, aos poucos, a influenciar as lideranças operárias que encontrou em Magé, aproximando-as da ideologia do PCB e, simultaneamente, conquistando respeito e admiração da comunidade, onde suas atividades médicas e comunistas se confundiam. "Dr. Irun é um grande homem, ele ainda está vivo, aquele era dos vermelhos mesmo". ${ }^{32}$

No período em que Dr. Irun Sant’Anna chegou a Magé, em 1940, no auge do Estado Novo, o PCB encontrava-se na clandestinidade, sob forte repressão. No próprio Sindicato de Santo Aleixo, todas as reuniões eram assistidas por um investigador policial, que, de praxe, era convidado a compor a mesa diretora durante as sessões.

\begin{abstract}
Tinha um famoso investigador [da Divisão de Ordem Política e Social (DOPS)] chamado Machado. Pra você ter uma idéia da repressão Getuliana nesse primeiro período... [...] Ele ia para todas as reuniões do Sindicato abertamente como investigador. Era convidado para sentar à mesa, como representante da polícia estadual. Isso em 40, 41. Então nossas reuniões [do $\mathrm{PCB}$ ] tinham que ser ultraclandestinas, pois as reuniões oficiais [no sindicato] eram monitoradas pelo investigador e com dirigentes ligados a Getúlio.33
\end{abstract}

Para além de sua ligação com os trabalhadores têxteis no cotidiano, o médico comunista também fomentou diversos movimentos ligados ao contexto internacional. A partir de 1942, sob sua orientação, foram realizadas em Magé campanhas contra o fascismo, pela declaração de guerra do Brasil contra o Eixo, pelo envio da Força Expedicionária Brasileira (FEB) para os campos da Europa e pelo apoio a esse contingente brasileiro guerreando na Itália. Chegou até a participar da criação do Comitê Democrático Progressista de Santo Aleixo, reunindo trabaIhadores, sindicalistas, empresários, comerciantes, religiosos e políticos. Além disso, se envolveu ativamente no desporto da cidade, ao participar da fundação do Nacional Futebol Clube, na sede do município, formado por guardas sanitários do Serviço Nacional de Malária, chegando a disputar o campeonato mageense, promovido pela recém-fundada Liga Mageense de Desportos (LMD): "por influência minha, a bandeira do time tinha que ser vermelha e ter uma estrela, já que a União Soviética, além da foice e do martelo, tinha uma estrela dourada". ${ }^{34}$

Como se vê, a partir de um discurso "patriótico e nacionalista", o médico contribuiu para uma efervescência política bastante significativa na cidade. Desse modo, sua atuação em Santo Aleixo no período da guerra nos remete às reflexões de Savage, de que não apenas as interligações entre lugares distintos devem ser examinadas, "mas também como os mediadores espaciais - pessoas capazes de

31 Entrevista concedida por José Rodrigues, op. cit.

32 Entrevista concedida por Paulo Lopes a Juçara da Silva Barbosa de Mello, em 2005.

33 Entrevista concedida por Irun Sant’Anna, médico comunista, a Felipe Augusto dos Santos Ribeiro, em 06 de abril de 2006.

34 Idem. 
se moverem entre as escalas espaciais - podem vir a ter um papel-chave na geração de formas de mobilização política". ${ }^{35} \mathrm{E}$, a partir dessa rede de contato face a face, outros instrumentos importantes foram se consolidando com os tecelões da Fábrica Santo Aleixo, como a imprensa.

O jornal Tribuna Popular, por exemplo, fundado em 22 de maio de 1945 pelo PCB, serviu como um importante instrumento de agitação operária e de difusão das ideias do partido. Em suas edições, mantinha uma página exclusiva para assuntos esportivos, além de colunas permanentes para a prestação de contas das ajudas ao Movimento de Auxílio à Imprensa Popular (MAIP) e seu plano financeiro, divulgação de livros e congressos do partido, anúncios e classificados. Publicava periodicamente notícias sobre o movimento operário brasileiro e internacional, as vitórias comunistas em diversos parlamentos pelo mundo e a cobertura da atuação dos parlamentares comunistas no país. Artigos de Luiz Carlos Prestes e outros líderes do partido também eram frequentemente publicados. Dando início a uma estratégia bastante eficaz na conquista de maior reconhecimento entre os trabaIhadores e na demonstração da força de suas ideias, começaram a ser publicadas diversas reportagens sobre o ambiente operário em Santo Aleixo. Uma delas, inclusive, chegou a publicar sobre uma festa em Santo Aleixo pró-Imprensa Popular, organizada pelos comunistas. O evento foi realizado ao ar livre, em estilo junino, com baile e barraquinhas, e contou com a participação de um conjunto regional de Santo Aleixo, promovendo um "concurso de calouros" e distribuindo vários prêmios. Além disso, houve um espetáculo teatral com artistas trazidos do Distrito Federal pelo próprio MAIP. ${ }^{36}$

No contexto específico da guerra, o Tribuna Popular fez a cobertura da inauguração da sede do PCB em Santo Aleixo, em 1945, tendo os dirigentes locais do partido tratado dos problemas mais sentidos pelos trabalhadores, tais como a falta de leite (que prejudicava o combate à mortalidade infantil e às enfermidades da criança); a quantidade escassa de escolas para a juventude; as fábricas de tecidos não possuem refeitório, obrigando muitos operários a se alimentar "sentados na calçada”; as precárias instalações elétricas e sanitárias; até a construção de pontes no distrito. Destaca-se que nesse momento o grupo Bezerra de Mello já estava à frente da fábrica há quatro anos.

[...] A coletividade obreira e o povo não desfrutam dos benefícios que
Ihes deviam caber na riqueza criada por todos [...] Convém dizer que
os industriais de Santo Aleixo tem aceitado algumas reivindicações da
massa operária e prometem estreitar daqui por diante os entendimen-
tos para resolver as questões de interesse comum, como a que se faz
no momento referente a melhoria dos salários. Estamos certos, de qual-
quer modo, de que a nossa atitude, estendendo a mão à burguesia pro-
gressista, há de ser compreendida pelos industriais das fábricas de teci-
dos do lugar. Da nossa parte, continuaremos a pregar de acordo com as
diretrizes do Partido e de nosso dirigente máximo Luis Carlos Prestes,
a política de cooperação entre as classes e as correntes democráticas
para resolver pacífica e unitariamente os grandes e complexos proble-
mas locais, estaduais e nacionais. [...] E na realidade somos uma força. O
Partido em Santo Aleixo cresce como uma planta de ramos largos [...].37

35 SAVAGE, op. cit., 2004, p. 42.

36 Tribuna Popular, 12 de setembro de 1947, p. 8.

37 Tribuna Popular, 29 de junho de 1945, p. 2 e p. 8, passim. Entrevista concedida pelo dirigente José Aquino de Santana. 
A postura tomada pelo $\mathrm{PCB}$ na articulação com os tecelões de Santo Aleixo tornou-se decisiva, sobretudo por não renegar suas experiências anteriores, mas legitimando-as como parte do processo de aprendizado desses trabalhadores, ${ }^{38}$ como podemos perceber numa entrevista concedida pelo contramestre da Fábrica Santo Aleixo, Agenor José dos Santos, ao Tribuna Popular, em 1946:

O Sr. Já ouviu falar na "União dos Operários das Fábricas de Tecidos"
de Santo Aleixo? Pois então escute. Quando acabou a Primeira Guerra
Mundial em 1918, correu aqui um boato de que a revolução social havia
estourado na Europa e no Rio de Janeiro. Imediatamente os líderes da
União dos Operários das Fábricas de Tecidos, entre eles, o velho Gui-
lhermino, fizeram um comício e depois marcharam a pé com o povo de
Santo Aleixo com destino a Magé. O objetivo era tomar a cidade e dar-
-lhe um governo nitidamente operário e popular. Lá chegando o povo,
que estava desarmado, foi recebido e dispersado a bala por forças po-
liciais. Alguns de seus líderes foram presos e torturados selvagemente,
outros caçados como feras pelos matos. Vive aqui ainda um velho, que
dormiu dentro de um buraco, feito [no meio do] mato, durante mais de
15 noites. ${ }^{39}$

Desse modo, é possível perceber que, na medida em que o grupo Bezerra de Mello produzia uma nova relação com os operários de sua fábrica, o PCB também construía um forte discurso de mobilização com o mesmo grupo de trabalhadores. Ambos lucraram durante o contexto da guerra (sejam dividendos políticos e/ ou financeiros) e souberam articular muito bem os temas gerais e locais que eram caros naquele momento, intensificando vínculos "densos" e "de amplo alcance".

Em âmbito nacional, foram decisivos para essa efervescência os discursos contra o fascismo e a pró-democracia, o advento do trabalhismo, as campanhas populares de apoio à FEB, o fim do longo período ditatorial do Estado Novo, o retorno do processo eleitoral no país e o surgimento de um eleitorado que incorporou parte significativa dos trabalhadores. Já no municipal, o reconhecimento dos sindicatos têxteis, as novas administrações fabris que consolidaram o padrão "fábrica-vila operária" e ampliaram as oportunidades de emprego, a incorporação das "lutas do passado" dos tecelóes mageenses pelo PCB e a reunião de diversos setores da sociedade local para discutir "política” também foram cruciais.

Além disso, uma análise de diversas reportagens publicadas no Tribuna Popular nos levou a perceber o quanto essas reuniões foram dando lugar, paulatinamente, a intensas disputas políticas, sendo o Comitê Democrático Progressista um bom exemplo disso.

Embora fossem instrumentos fomentados pelo próprio PCB e amplamente divulgados no jornal do partido por meio da coluna "A vida dos comitês populares", ao congregar na mesma mesa trabalhadores locais, diretores sindicais nomeados como interventores, comerciantes, empresários, gerentes das fábricas de tecidos, o padre paroquiano e o próprio prefeito da cidade, esses comitês foram decisivos para o desenvolvimento de ideias e práticas voltadas para a democracia. Eles contribuíram para a construção de "relações de classe de novo tipo", como afirmou um tecelão de Magé à época. Tudo isso no imediato pós-guerra, em $1945 .{ }^{40}$

38 Tribuna Popular, 04 de julho de 1945, p. 8. Na reportagem de primeira página, "Santo Aleixo é o $1^{\circ}$ distrito do Brasil a ter inaugurada a sede do P. Comunista", o jornal enfatizou que o local "tem uma grande tradição de luta patriótica e antifascista", onde "o integralismo não conseguiu penetrar".

39 Tribuna Popular, 13 de abril de 1946, p. 8.

40 Os comitês eram incentivados por Prestes como forma de desmascarar os demagogos e provocadores fascistas: "pela organização do povo em organismos que lhe sejam próprios, em amplos comitês ou comissões nos locais de trabalho, nas ruas e bairros, comitês populares democráticos que, unidos, 
Após um período de organização provisória, foi empossada a primeira diretoria eleita do comitê de Santo Aleixo, tendo como presidente o então subdelegado de polícia, Georgino Ferreira de Mesquista, que mais tarde seria tachado pelos comunistas como "perseguidor de operários". Já o PCB obteve duas vagas na direção, com José Muniz de Melo e Pompeu Hortêncio Pereira na Comissão de Finanças. Como orador na cerimônia de posse, destaca-se o Juiz de Paz Álvaro Teixeira Pinto, que era membro do Partido Social Democrático (PSD). ${ }^{41}$

Em seguida, o comitê realizou uma espécie de sabatina com o prefeito Ivan Mariz no sindicato dos têxteis, estando também presente o gerente da Fábrica Santo Aleixo. De acordo com o Tribuna Popular, o prefeito sentiu-se bem em tratar face a face com o povo, discutindo os problemas que mais afligiam a população, e "logo surgiram do próprio seio da massa vozes que falavam ao prefeito das mais sentidas reivindicações locais". 42

Para os trabalhadores, particularmente, a reunião de diversos setores da sociedade dedicados a discutir "política" foi essencial para as transformações que estavam por vir, como o fim do longo período ditatorial do Estado Novo, o retorno do processo eleitoral no país e a incorporação de parte significativa dos trabalhadores neste novo eleitorado. Nesse sentido, a fala do tecelão comunista Germano Narciso é bastante interessante:

[...] Convém dizer que os industriais de Santo Aleixo têm aceitado algumas reivindicações da massa operária e prometem estreitar de aqui por diante os entendimentos para resolver as questões de interesse comum. [...] Estamos certos [...] de que a nossa atitude de estender a mão à burguesia progressista, há de ser compreendida pelos industriais de fábricas têxteis do lugar. ${ }^{43}$

Vale ressaltar que, entre esses "industriais progressistas", encontrava-se o grupo Bezerra de Mello, que havia recém adquirido a Fábrica Santo Aleixo e, de fato, buscou dialogar com a classe trabalhadora local, principalmente no período do chamado "esforço de guerra", quando o governo brasileiro decretou uma série de leis que, respondendo às pressões dos industriais, em particular os têxteis, suspendia a vigência de diversos direitos trabalhistas, visando estimular a produção durante a guerra. Da mesma forma, a organização local que congregava o contingente mais significativo de operários - o PCB — difundia a tese de União Nacional, "estendendo a mão" ao governo e aos industriais. ${ }^{44}$

Entretanto, as relações amistosas no Comitê foram bastante abaladas após uma conferência religiosa organizada no Cine Andorinhas, de propriedade da fábrica

pouco a pouco, de baixo para cima, constituirão, num futuro mais ou menos próximo, as organizações democráticas populares da cidade, região e Estado até a grande união nacional [...]" Manifesto: União Nacional para a democracia e o progresso, em 23/05/1945. In: CARONE, Edgar. O PCB (1943-1964). Coleção Corpo e Alma do Brasil. São Paulo: Difel, 1982. v. 2. p. 36-37. Sobre outros trabalhos que abordaram a atuação dos comitês populares, Cf.: FRENCH, John D. O ABC dos operários: conflitos e alianças de classe em São Paulo, 1900 -1950. São Caetano do Sul, SP: HUCITEC; Prefeitura Municipal de São Caetano do Sul, 1995; e SILVA, Leonardo Ângelo da. Industrialização, relações de classe e participação política: da criação da CSN à emancipação de Volta Redonda (1941-1954). Dissertação (Mestrado em História Social). Universidade Federal Rural do Rio de Janeiro - UFRRJ, Seropédica, RJ, 2010.

41 Tribuna Popular, 03 de julho de 1945, p. 2.

42 Tribuna Popular, 04 de agosto de 1945, p. 8.

43 Tribuna Popular, 29 de junho de 1945, p. 2.

44 O PCB havia reconquistado a legalidade e, logo em seguida, o líder comunista Luiz Carlos Prestes foi libertado da prisão. Em seus primeiros discursos, declarou apoio à permanência de Getúlio Vargas no poder e difundiu a tese da "União Nacional", tendo em vista que o Brasil, ao declarar guerra à Alemanha e à Itália, tornou-se um aliado da União das Repúblicas Socialistas Soviéticas (URSS). 
homônima. Na ocasião, o orador convidado para o evento, Monsenhor Uchôa, teria afirmado que entre o comunismo e o nazismo preferia este último para o Brasil. E disse isso justamente nas cercanias da fábrica dos alemães Mattheis e ainda em um evento apoiado pelo Círculo Operário Católico na região, grupo que disputava espaço com o PCB junto aos operários. Foi o suficiente para o membro da Comissão de Finanças do comitê, Pompeu Hortêncio, que também era Secretário Político do PCB local, enviar um telegrama de protesto em nome do Comitê Democrático Progressista ao presidente Getúlio Vargas relatando o ocorrido. ${ }^{45}$ Pouco depois, o próprio Hortêncio se retratou, explicando que a responsabilidade pelo envio do telegrama era dele, sendo assim, uma iniciativa individual e não uma opinião do comitê. ${ }^{46}$

Para completar o quadro de disputas políticas, poucas semanas após a deposição de Getúlio Vargas, o PCB reformulou sua diretiva queremista e resolveu lançar candidato próprio a presidente: ledo Fiúza. Em Magé, a campanha do partido foi intensa e provocou reações.

Embora elogiassem a eleição da nova diretoria para o Sindicato de Santo Aleixo, até então ocupada por um interventor, no início de 1946, logo os comunistas iriam perceber que não eram bem quistos por lá. O presidente eleito Jair Rosa de Arruda, o "Zica", que chegou a ser apontado pela polícia política como consultor do partido, posteriormente passou a ser considerado uma "pedra no sapato dos comunistas".

[...] Primeiro ele [Zica] chegou a tentar se filiar ao partido. Não sei se foi intenção da polícia de metê-lo como coisa... Mas depois ele se afastou e virou um inimigo direto [...]. Pra você ter uma idéia, tendo ligação com a massa, nós [os comunistas] promovíamos todos os sábados e domingos um baile na sede do Sindicato. E sabe o que o "Zica" fez? Mandou pregar as cadeiras e daí acabou! Como tu ia fazer o baile? O negócio era assim feroz! ${ }^{47}$

Logo em seguida, o comunista Pompeu Hortêncio Pereira sofreria um atentado ao sair do sindicato, sendo agredido a pauladas e ferido com canivete, episódio bastante explorado pela imprensa do partido. ${ }^{48} \mathrm{Em}$ seguida, foram registradas pelo jornal iniciativas que seriam interpretadas como uma tentativa de "acabar com os comunistas": a chegada de um promotor público para fixar residência nas proximidades do sindicato, a criação do Centro Pró-Melhoramentos de Magé - "repleto de integralistas" - em concorrência ao comitê, e a perseguição empreendida pelo subdelegado a muitos operários ligados ao partido.

Nas comemorações do Dia do Trabalho pelo Sindicato de Santo Aleixo, em 1947, quando também eram celebrados os quatro anos de funcionamento da Escola Sindical $1 .^{\circ}$ de Maio, lá estava no palanque o então candidato a prefeito de Magé, José Ullmann Júnior, do PSD. Ele já havia ocupado o cargo de prefeito em 1936, tendo permanecido nele por nomeação do interventor estadual após o Estado Novo, e agora buscava estabelecer ligações com os sindicatos do município. Mais tarde, a própria direção da Fábrica Santo Aleixo iria se aproximar e apoiar a atuação de líderes pessedistas, com destaque para o comerciante Waldemar Lima Teixeira, que se tornou o principal líder do partido no município.

45 Tribuna Popular, 17 de outubro de 1945, p. 4.

46 Tribuna Popular, 25 de outubro de 1945, p. 3.

47 Entrevista concedida por Irun Sant'Anna. op. cit.

48 Tribuna Popular, 04 de abril de 1946, p. 8. 
No aspecto religioso, convém destacar que as ações da Igreja Católica eram sempre apoiadas pela irmã do proprietário da Fábrica Santo Aleixo, Alcina Lynch Bezerra de Mello, responsável pela política social da empresa, participando, inclusive, da criação do Apostolado da Oração na comunidade, em agosto de 1944. Em outubro do mesmo ano, ela tornou-se presidente do grupo, tendo o pároco de Magé, padre José Galdino da Costa, como diretor. ${ }^{49}$ Todavia, no ano seguinte, "Dona Alcina" despediu-se temporariamente do Apostolado de Oração, em virtude de uma viagem que faria ao Recife, cidade onde a Companhia Bezerra de Mello também possuía fábrica de tecidos.

Em seguida, chegou a Santo Aleixo o padre José de Albuquerque, designado para a função de capelão das duas fábricas. O sacerdote criou o Círculo Operário Católico na região, realizava vários atendimentos às famílias operárias e também organizava muitas procissões, nas quais recitava preces como "Livrai-nos, Senhor, do comunismo ateu" e os fiéis respondiam em coro "Amém".

Logo, a relação entre os militantes do PCB e a direção da Fábrica Santo Aleixo também sofreria um forte revés. Em vez de "estender a mão", os comunistas iniciaram uma intensa campanha contra o grupo Bezerra de Mello, publicando diversas reportagens no Tribuna Popular. Uma delas, intitulada "Trágica a situação de milhares de tecelões de Santo Aleixo e Magé”, mostrava fotos de tecelões em sua hora de almoço, realizando refeições em marmitas e agachados na calçada em frente à Fábrica Santo Aleixo, pois não havia refeitórios. Além disso, questões salariais, de acesso a serviços de saúde, entre outras reivindicações, eram direcionadas ao "conhecido senhor feudal Bezerra de Mello, poderoso industrial de Pernambuco". ${ }^{50}$

\section{Conclusão}

A teoria das redes proposta por Savage, aplicada a pesquisas empíricas sobre os operários-moradores de Santo Aleixo, possibilitou uma breve reflexão sobre o quão é complexa a análise de formação da classe, sobretudo quando se busca superar os "tipos ideais" ainda em voga nas discussões acadêmicas.

O presente artigo - longe de esgotar este debate - apresenta as experiências dos tecelões de Santo Aleixo como interessante objeto para a análise de redes de contato, particularmente durante a Segunda Guerra, quando ocorreram intensas transformações no local de trabalho e na vida fora das fábricas. Para além das experiências locais anteriores, outros fios são incorporados a essa rede, como, por exemplo, as trajetórias do empresário Bezerra de Mello e do PCB, que desembocaram simultaneamente naquele lugar, fundindo-se e concorrendo com outras trajetórias e identidades.

No período pós-guerra, ao passo que o grupo empresarial Bezerra de Mello progredia, adquirindo novas máquinas, ampliando o prédio da Fábrica Santo Aleixo, apresentando uma série de benefícios sociais aos seus trabalhadores e até incorporando boa parte dos operários demitidos por outra empresa que mantinha uma fábrica de tecidos em Magé, ${ }^{51}$ o PCB, por sua vez, conseguiu formar um considerável

49 Dados compilados do $1 .^{\circ}$ Livro de Atas do Apostolado de Oração de Santo Aleixo. Acervo: Ademir Calixto Oliveira.

50 Tribuna Popular, 17 de fevereiro de 1946, p. 8.

51 "Certa ocasião, a Fábrica Itatiaia [localizada no centro de Magé] parou de funcionar e as duas fábricas de Santo Aleixo mantiveram mais de 50\% dos funcionários daquela fábrica". Entrevista concedida pelo exoperário e jogador de futebol Casimiro Virgínio da Rocha a Felipe Augusto dos Santos Ribeiro, em 1999. 
contingente de tecelões ligados ao partido, elegendo muitos deles como dirigentes sindicais e também como vereadores em todos os pleitos municipais, entre 1947 e 1962, por meio da legenda de outros partidos.52

Tudo isso gerou um complexo de redes muito bem tecido, no qual concepções como a da "nuvem de paz" e a do "dragão que comia gente" do Meu Pé de Laranja Lima estão ali, sem determinações a priori, confrontando-se, imbricando-se e revelando-se de maneiras diversas, ora evidenciando o consenso, ora o conflito. Nesse sentido, é significativa a constatação de que o período entre as décadas de 1940 e 1960 se configura para os tecelões da Fábrica Santo Aleixo (Esther) como um "lugar de memória", no qual a valorização de uma harmonia social entre trabalhadores e patrões convive com um certo orgulho do lugar ter sido conhecido como um "Moscouzinho", devido às lutas operárias.

De fato, o compasso da vida dos trabalhadores têxteis santoaleixenses normalmente seguia o ritmo das fábricas e, quando elas deixaram de funcionar, era como se suas vidas tivessem parado de rodar. Por isso mesmo, quando a Fábrica Santo Aleixo fechou definitivamente suas portas, no final da década de 1970, uma nostalgia daqueles tempos áureos passou a ser recorrente e permanece até hoje. No imaginário de alguns trabalhadores, a expectativa de que a fábrica possa "voltar a rodar" talvez signifique que, com a volta do trabalho fabril, volte também todo aquele tempo passado de certo modo ainda presente, pois mantido vivo pela memória. Um dos símbolos dessa expectativa é a própria sede do Sindicato de Santo Aleixo, que, apesar da falência das indústrias têxteis no município, ainda está lá de pé e em funcionamento, como se estivesse à espera de novos embates, novas greves em prol do operariado.

Em suma, o processo da formação de classe dos operários-moradores de Santo Aleixo foi marcado pela formação de densas redes comunitárias, forjadas nas relações de parentesco e vizinhança que caracterizam as identidades locais, mas também pelos vínculos criados em torno da centralidade do trabalho fabril, a partir das experiências no chão da fábrica e do cruzamento com outras redes de solidariedade, de longo alcance. Essa constatação traz à tona muitas questões e nos faz vislumbrar muitas evidências, das quais citamos ao menos uma: que o estudo da história de grupos operários de locais específicos, afastados dos grandes centros, apresenta outras possibilidades e novas densidades para a História do Trabalho no Brasil como um todo.

Recebido em 25/04/2013

Aprovado em 20/10/2013

52 Em 1947, foram eleitos pelo Partido Trabalhista Brasileiro (PTB) o médico Irun Sant'Anna, o comerciante e ex-operário têxtil José Muniz de Melo (licenciado durante o mandato), os tecelões Feliciano Costa e Agenor dos Santos, e o ex-operário da Fábrica de Pólvora Argemiro da Cruz Araújo (suplente empossado durante o mandato). Esses vereadores tiveram seus mandatos cassados arbitrariamente em 1948 e os tecelões que militavam no partido foram duramente perseguidos, inclusive com presença policial dentro das fábricas. Em 1950, elegeram-se pelo Partido Trabalhista Nacional (PTN) o eletricitário José Aquino de Santana, o tecelão Petronilho Alves (diplomado e empossado somente no final do mandato) e a tecelã Ilza Gouvea (suplente empossada no início do mandato). Em 1954, foi eleito pelo Partido Socialista Brasileiro (PSB) o líder camponês e ex-operário têxtil Manoel Ferreira de Lima. Em 1958 e em 1962, foram eleitos e reeleitos pelo PSB os operários Astério dos Santos e Darcy Câmara. 